ORIGINAL ARTICLE

\title{
Significant expression of IGFBP2 in breast cancer compared with benign lesions
}

\author{
L-T Busund, E Richardsen, R Busund, T Ukkonen, T Biørnsen, C Busch, H Stalsberg
}

J Clin Pathol 2005;58:361-366. doi: 10.1136/icp.2004.020834

See end of article for authors' affiliations

.....................

Correspondence to:

Dr L-T R Busund,

Department of Pathology,

University Hospital of

Northern Norway, 9038

Tromsø, Norway; lill.tove.

busund@unn.no

Accepted for publication

13 September 2004
Background/Aim: Insulin-like growth factors (IGFs) and IGF binding proteins (IGFBPs) play a role in the normal development of breast tissue, and possibly in breast cancer aetiology. IGFBP2, one of six members of the IGFBP superfamily, acts as regulator of the IGFs and has pleiotropic effects in normal and neoplastic tissues. Because IGFs have mitogenic effects on mammary epithelia, this study investigated IGFBP2 expression in mammary tissues of different benign and malignant entities.

Methods: Immunohistochemistry was used to study correlations between the presence and intensity of IGFBP2 staining and tumour type and grade, in addition to steroid hormone receptor status, in 120 breast specimens. Expression was measured by quantitative colour video image analysis and semiquantitative evaluation, and the measurements correlated well $(r=0.92 ; p<0.05)$.

Results: Both methods found no significant expression of IGFBP2 in normal glandular cells and hyperplasia (group I). Atypical hyperplasia showed a slightly increased cytoplasmic expression of IGFBP2, and carcinoma in situ showed a distinctive, membrane associated and cytoplasmic expression (group II). Infiltrating carcinomas strongly expressed cytoplasmic IGFBP2 (group III). There were significant differences between group I and II, and between group II and III. There were no significant differences between invasive lobular and invasive ductal carcinoma, or between grades I, II, and III within these entities. There was no significant correlation between IGFBP2 immunostaining and oestrogen or progesterone receptor positivity within the malignant group.

Conclusions: IGFBP2 mitogenic signals of autocrine/paracrine regulatory mechanisms may be responsible for the growth of breast carcinomas and IGFBP2 may be an independent indicator of malignancy.
I nsulin-like growth factors (IGFs) and IGF binding proteins (IGFBPs) play important roles in cellular growth and development in both normal and neoplastic tissues. ${ }^{12}$ IGFs promote the growth of a range of tumour types, including mammary carcinoma, and enhance the proliferation of several mammary carcinoma cell lines. Because IGFs have mitogenic effects on mammary epithelia, ${ }^{12}$ attention has been focused on the role and localisation of the IGFBPs in benign and malignant mammary tissues.

"Insulin-like growth factors promote the growth of a range of tumour types, including mammary carcinoma"

IGFBP2 is not glycosylated and contains an integrin receptor recognition sequence, suggesting that it has cell association properties, ${ }^{3}$ which may be necessary for its actions, because mutation of the membrane binding domain has been reported to block IGFBP2 potentiation of IGF2 stimulated mitogenesis. ${ }^{4}$ The cellular actions of IGFBP2 on IGF mediated functions have been reported to be both inhibitory and stimulatory. ${ }^{5}$ By using homologous recombination and embryonic stem cell technology to generate mice in which the IGFBP2 gene was mutated, ${ }^{6}$ few developmental abnormalities were discovered. IGFBP2 expression was found to be reduced in lung carcinoma cell lines, and was inhibitory to IGF2 action when added exogenously. ${ }^{7}$ We have previously shown the increased expression of IGFBP2 in prostatic intraepithelial neoplasia and invasive prostatic carcinoma, compared with normal prostatic glands. ${ }^{8}$ We have also shown a significant correlation between malignant potential in adult soft tissue sarcomas and the expression of IGF mitogenic signals. ${ }^{9}$
Most of the scientific literature to date focuses on the expression of IGFBP2 in malignant, but not normal, breast epithelial cells. In our study, we have used an immunohistochemical approach to clarify the expression and localisation of IGFBP2 in malignant and benign breast tissues.

\section{MATERIALS AND METHODS \\ Case selection}

Our study material consisted of 120 archival surgical breast resections from the department of pathology, University Hospital of Northern Norway. Histological classification of breast diseases was made according to the criteria of the World Health Organisation. ${ }^{10}$ Invasive ductal carcinomas were further divided into three subgroups according to the modified Bloom and Richardson classification. ${ }^{11}$ The series included invasive lobular carcinomas, invasive ductal carcinomas of grade I, II, and III, ductal or lobular carcinoma in situ, atypical ductal or lobular hyperplasia, ductal or lobular hyperplasia, non-proliferative fibrocystic change, and breast specimens from women showing no histological abnormalities. All the normal breast specimens and benign breast lesions were from patients without cancer. The breast specimens were selected from the four most recent years of the archive. There were no major changes to the procedures in the laboratory during this period. No appreciable differences in staining intensity could be detected in the earliest diagnosed specimens compared with the latest one

Abbreviations: $E R$, oestrogen receptor; $D A B$, diaminobenzidine tetrahydrochloride; IGF, insulin-like growth factor; IGFBP, insulin-like growth factor binding protein; IR, immunoreactivity score; PBS, phosphate buffered saline; PR, progesterone receptor; VIA, video image analysis 
Table 1 Distribution and grouping of histological diagnosis, hormone receptor status of malignant cases, and patient age

\begin{tabular}{|c|c|c|}
\hline Characteristics & $\mathrm{N}$ & $\%$ \\
\hline \multicolumn{3}{|l|}{ Group I } \\
\hline Normal & 11 & 9 \\
\hline Non-proliferative fibrocystic change & 12 & 10 \\
\hline Ductal or lobular hyperplasia & 9 & 8 \\
\hline \multicolumn{3}{|l|}{ Group II } \\
\hline Atypical ductal or lobular hyperplasia & 11 & 9 \\
\hline Ductal/lobular carcinoma in situ & 13 & 11 \\
\hline \multicolumn{3}{|l|}{ Group III } \\
\hline Ductal carcinoma, grade I & 17 & 14 \\
\hline Ductal carcinoma, grade II & 19 & 16 \\
\hline Ductal carcinoma, grade III & 15 & 12 \\
\hline Lobular carcinoma, grade I-III & 13 & 11 \\
\hline Total specimens & 120 & 100 \\
\hline \multicolumn{3}{|l|}{ Hormone receptor status (group III) } \\
\hline ER+ & 34 & 53 \\
\hline ER- & 30 & 47 \\
\hline $\mathrm{PR}+$ & 33 & 52 \\
\hline PR- & 31 & 48 \\
\hline \multicolumn{3}{|l|}{ Mean age (years) } \\
\hline Group I & \multirow{3}{*}{\multicolumn{2}{|c|}{$\begin{array}{l}54 \text { (range, 22-68) } \\
52 \text { (range, 29-62) } \\
59 \text { (range, 32-90) }\end{array}$}} \\
\hline Group II & & \\
\hline Group III & & \\
\hline \multicolumn{3}{|l|}{ Menopausal/postmenopausal } \\
\hline Group I & 25 & $78 \%$ \\
\hline Group II & 20 & $83 \%$ \\
\hline Group III & 60 & $92 \%$ \\
\hline
\end{tabular}

diagnosed. From 10 to 20 specimens were selected randomly from the different entities.

Haematoxylin and eosin stained sections from formaldehyde fixed and paraffin wax embedded breast tissues were reviewed independently by two pathologists (HS and LTB) to establish the diagnosis.

\section{Immunohistochemistry}

For each procedure, the order of samples was chosen randomly from each of the groups. A standard immunohistochemical method was performed. The $4 \mu \mathrm{m}$ thick sections of phosphate buffered saline (PBS)/formalin fixed and paraffin wax embedded specimens were routinely dewaxed in xylene, rehydrated in a graded series of ethanol, and washed in distilled water. Antigen retrieval was achieved by placing the specimens in $0.01 \mathrm{M}$ citrate buffer at $\mathrm{pH} 6.0$ and exposing them to repeated microwave heating for periods of 10 minutes at $450 \mathrm{~W}$. The buffer was replenished after each interval because of evaporation. The specimens were cooled at room temperature for 15 minutes and washed in sterile water for five minutes and then in PBS at $\mathrm{pH} 7.6$ for five minutes. Endogenous peroxidase or phosphatase activities were quenched in $0.3 \% \mathrm{H}_{2} \mathrm{O}_{2} / \mathrm{H}_{2} \mathrm{O}$ (Sigma, St Louis, Missouri, USA) for 30 minutes, followed by blocking of non-specific antibody binding in $10 \%$ goat serum for 30 minutes at room temperature. Tissue sections were incubated overnight at $4^{\circ} \mathrm{C}$ in a humidifier with primary goat anti-IGFBP2 (Santa Cruz Biotechnology, Santa Cruz, California, USA; polyclonal antibody diluted $1 / 150$ in $1 \%$ bovine serum albumin). As negative staining controls, the antibodies were replaced with either $1 \%$ bovine serum albumin in PBS to rule out the effect of endogenous peroxidase, or isotype matched irrelevant mouse immunoglobulin to test for specificity. The specificity of the antibody was also confirmed by western blotting. Biotinylated rabbit antigoat $\mathrm{F}\left(\mathrm{ab}^{\prime}\right)_{2}$ fragments (Dako, Carpinteria, California, USA; diluted 1/400) were used as the secondary antibody. Specific intracellular immunoreactivity was detected by incubation with avidin-biotin-horseradish peroxidase complex for 30 minutes at room temperature. After extensive washing in PBS, the bound antibody was detected with a three stage avidin-biotinperoxidase complex technique using diaminobenzidine tetrahydrochloride (DAB) as chromogen (Dako). The specimens were counterstained in haematoxylin, dehydrated in a graded series of ethanol, cleared in three changes of xylene, and mounted in Eukitt. Appropriate positive and negative controls were included in each antibody run. No significant variations could be seen between different immunohistochemistry runs by repeating $10 \%$ of the batches.

The demonstration of oestrogen receptors (ERs), using antibody 1D15 (Dako), and progesterone receptors (PRs), using antibody NCL-PGR (Abbott Laboratories, Maidenhead, UK), was performed on paraffin wax embedded sections, according to a previously published protocol. ${ }^{12}$

\section{Semiquantitative analysis}

The degree of expression of IGFBP2 was then graded semiquantitatively and classified into one of four grades. The staining was scored as: 0 , no staining; 1, weak staining; 2 , strong staining of $25 \%$ tumour cells or moderate staining of $<80 \%$; 3 , strong staining of $25-50 \%$ or moderate staining of $>80 \% ; 4$, strong staining of $>50 \%$ tumour cells. In each case, 10 high power fields of representative areas were counted. The maximal staining intensity was typically higher in those cases where more cells were positive. Most positive cells showed cytoplasmic staining. In less than $1 \%$ of the cytoplasmically weak stained cells, an apparent coexistent membrane staining was seen. However, on closer inspection, this membrane staining was found to result from margins of epithelial cells pushing against necrotic lumina of carcinoma in situ. This pseudostaining of the membranes never exceeded the cytoplasmic level of staining, and was therefore recorded as cytoplasmic staining. Slides were examined and scored independently by two of the authors (TB and LTB), blinded to other pathological information. In $80 \%$ of cases, the data were similar, and the remaining cases were reviewed until final agreement was achieved.

The staining of ERs and PRs was estimated using the "quick score" technique, ${ }^{13}$ as follows: slides were assessed for both the proportion of cells stained and staining intensity. Proportions were scored as 0, 0\%; 1, 1-25\%; 2, 25-50\%; 3, 50$75 \%$; or $4,75-100 \%$ stained cells. The intensity was scored as 0 , no staining; 1 , weak; 2 , moderate; or 3 , strong staining. The two scores were added to give a final score of 0-7. A final score $<3$ was regarded as negative.

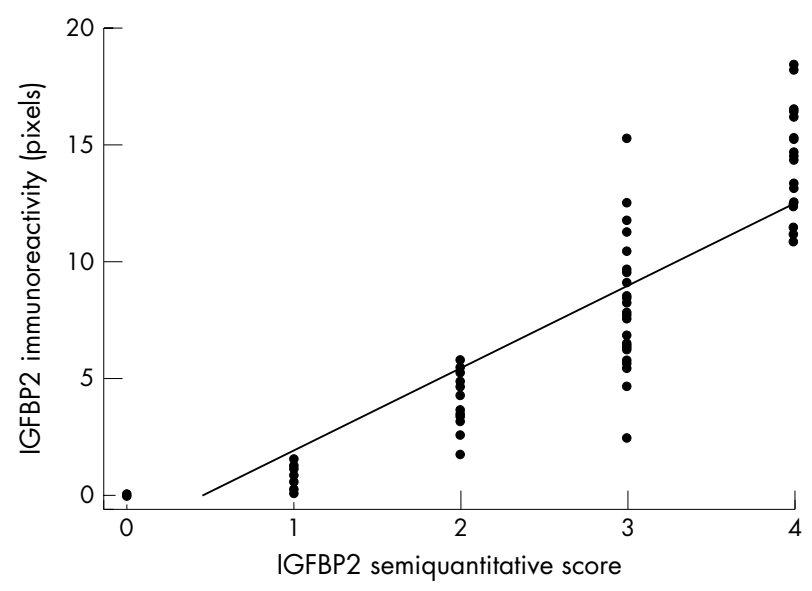

Figure 1 The two procedures, quantitative colour video image analysis and semiquantitative evaluation, correlated well for insulin-like growth factor binding protein 2 (IGFBP2) measurement (Spearman's correlation coefficient, $r=0.92 ; p<0.001)$. 


\begin{tabular}{|c|c|c|}
\hline & Semiquantitative & Quantitative \\
\hline \multicolumn{3}{|l|}{ Group I } \\
\hline Normal breast tissue & $0.18(0.12)$ & $0.06(0.03)$ \\
\hline Non-proliferative fibrocystic change & $0.17(0.11)$ & $0.09(0.05)$ \\
\hline Hyperplasia & $0.67(0.17)$ & $0.58(0.15)$ \\
\hline \multicolumn{3}{|l|}{ Group II } \\
\hline Atypical hyperplasia & $1.27(0.19)$ & $1.99(0.45)$ \\
\hline Carcinoma in situ & $1.92(0.18)$ & $3.42(0.49)$ \\
\hline \multicolumn{3}{|l|}{ Group III } \\
\hline Ductal carcinoma, grade I & $2.94(0.18)$ & $7.33(0.96)$ \\
\hline Ductal carcinoma, grade II & $3.58(0.14)$ & $11.59(0.93)$ \\
\hline Ductal carcinoma, grade III & $3.33(0.16)$ & $11.52(0.97)$ \\
\hline Lobular carcinoma & $3.15(0.19)$ & $9.56(1.08)$ \\
\hline \multicolumn{3}{|l|}{ Dunnett's test } \\
\hline Group I v group II & $<0.001$ & $<0.001$ \\
\hline Group II $v$ group III & $<0.001$ & $<0.001$ \\
\hline Group I v group III & $<0.001$ & $<0.001$ \\
\hline
\end{tabular}

\section{Colour video image analysis}

The immunostained sections were examined using a Leica (Leitz Laborlux S; Leica, Wetzlar, Germany) microscope $(\times 400)$ coupled to a video camera (Sony Hyper HAD; colour CCD-IRIS/RGB; model DXC-151AP), connected to a computer aided colour video image analysis (VIA) system (MultiSync 3V; model JC-1535VMR; NEC Corporation, California, USA).${ }^{14}$ After being captured and digitalised on to the video screen, microscopic images were analysed using an image analysis software program (Leica Q500MC; Microsoft Windows hosted image analysis system; Leica Australia $\mathrm{P} / \mathrm{L}$ ). The images stored in the software were composed of up to $512 \times 512$ pixels separated into 8 bit brightness. The transmitted light intensity was standardised by using a fixed rheostat setting at the microscope light source. The stability of the light output was frequently checked during all procedures.

Because of the high cellularity of some samples, sequential fields were systematically examined using a $\times 40$ objective and a $\times 10$ eyepiece within a fixed frame of $45000 \times 450$ pixels $\left(0.2025 \mathrm{~mm}^{2}\right)$. Colour values for each of the red, green, and blue components were calculated for each pixel from 1 to 255. After counterstaining with Harris's haematoxylin, which allowed excellent separation from DAB staining, a cutoff value of 170 was determined for the blue colour component to exclude false or weakly positive staining. This value was chosen after experience from 10 slides (two from each group), which were originally analysed for this purpose.

Because of the heterogeneity of the tumour samples, 10 fields were examined for each slide. This number was determined using a progressive mean graph to achieve a meaningful result in statistical terms. Each slide was initially examined at $\times 10$ magnification for an overall view of the lesion and counterstain intensity. This practice allowed an area to be chosen that was the most representative, with no tissue folding or overlapping, and minimal background staining. The fields were then randomly selected within this area. The degree of staining intensity was estimated as the mean $\mathrm{DAB}$ area stained from a minimum of 900 cells in 10 microscopic fields at $\times 400$ magnification. Evaluation of the staining reaction was performed using the immunoreactivity (IR) score, which is the staining intensity in pixels multiplied by the percentage area stained.

Data from the VIA were divided into five distinct IR groups similar to the semiquantitative evaluation of staining. Cutoff points defining these groups were determined before analysis to ensure roughly equal numbers in each group. The IR scale was as follows: IR $0,(0,1)$; IR $1,(1,5)$; IR 2, $(5,80)$; IR 3, $(80,110)$; IR 4, $(110, \infty)$.

\section{Ethics clearance}

Our study was approved by the research ethics committee of Northern Norway (REK, Ref. 200303108-3/IAY/400).

\section{Statistical analysis}

Data are presented as mean (SEM). Associations between the semiquantitative estimates of the expression of IGFBP2 and the quantitative measurements by colour VIA analysis were tested by Spearman's correlation coefficient. Individual groups were compared using the parametric Students's $t$ test. The differences in expression of IGFBP2 between groups were determined by Dunnett's test. The relation between IGFBP2 expression and receptor status in malignant tissue was tested by the non-parametric Mann-Whitney $U$ test. All reported $\mathrm{p}$ values are two sided. For all these statistical analyses a $p$ value of $<0.05$ was considered significant.

\section{RESULTS}

\section{Characteristics of the 120 cases}

Table 1 shows the distribution and grouping of the histological diagnoses. Thirty two specimens were in group I, 24 were in group II, and 64 were in group III. The four subgroups in group III each consisted of 13 to 19 cases. Thirty four of the 64 cases in group III were ER positive and 33 were PR positive. The mean age of the patients in group III was slightly higher than in groups I and II. This difference was not significant. The percentage of menopausal and postmenopausal patients was slightly higher in group III compared with group II, and in group II compared with group I. This difference was not significant.

\section{Correlations between quantitative colour VIA and semiquantitative scores}

The two procedures, quantitative colour VIA and semiquantitative evaluation, correlated well for IGFBP2 measurement (Spearman's correlation coefficient, $r=0.92 ; \mathrm{p}<0.001$ ), as shown in fig 1.

\section{Expression of IGFBP2 in groups I, II, and III}

Table 2 shows the semiquantitative and quantitative scores of IGFBP2 expression in benign and malignant breast tissues. 

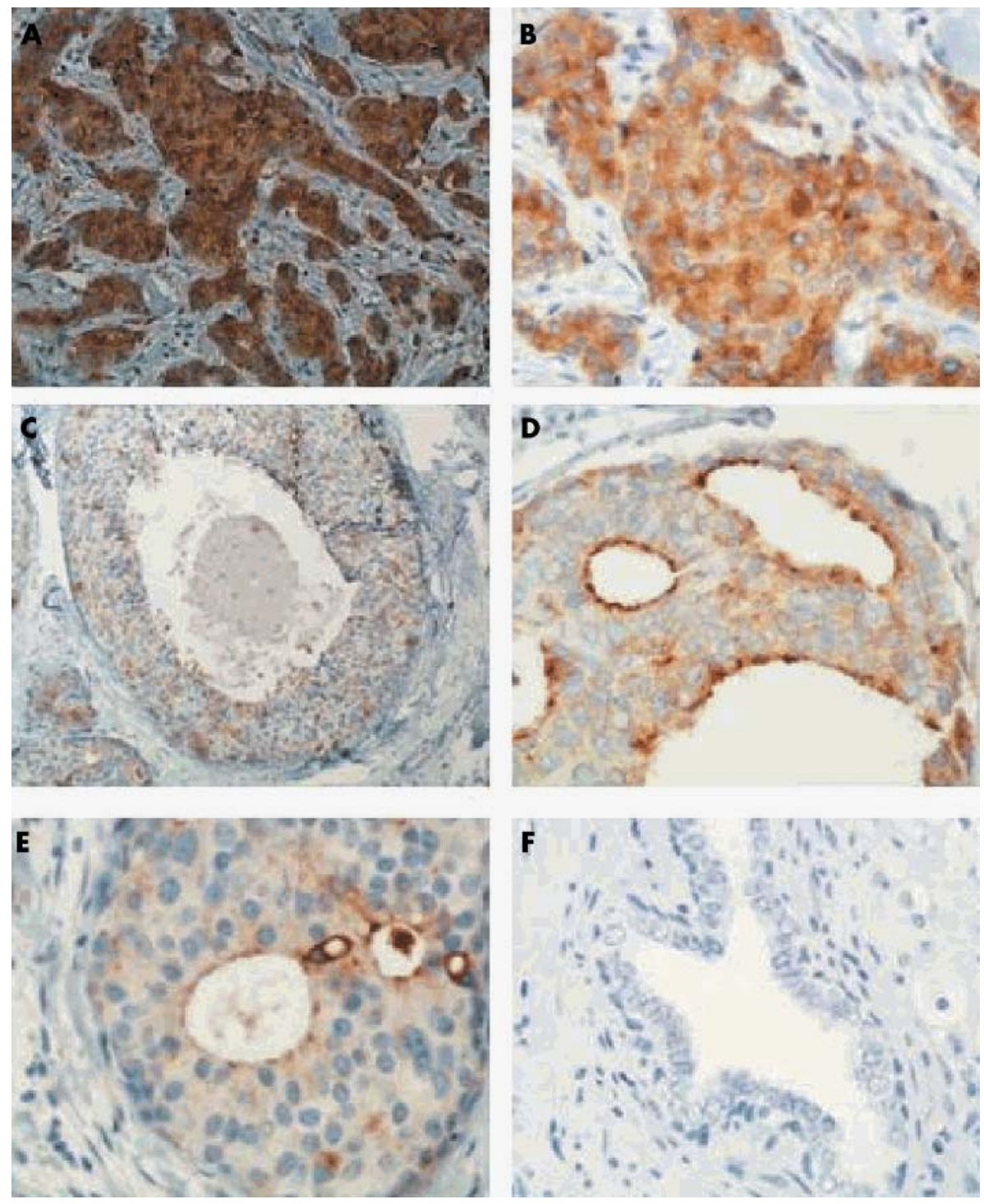

Figure 2 (A, B) Strong cytoplasmic staining for insulin-like growth factor binding protein 2 (IGFBP2) in the neoplastic cells of invasive ductal carcinoma. (C-E) Weak, dot-like positivity and abluminal staining of cribriform spaces for IGFBP2 in ductal carcinoma in situ. (F) Normal ducts show no staining.

The expression of IGFBP2 was mostly confined to the epithelial cells, with no appreciable stromal staining. Heterogeneity of staining, which was mostly intracellular, was noted within individual tumour samples, which showed either variations in intensity or patchiness of DAB staining. Significant differences in the immunohistochemical expression of IGFBP2 between the three histological groups were seen for both semiquantitative and quantitative scores $(\mathrm{p}<0.001)$. In group I, the quantitative data generated by colour VIA were between 0.06 and 0.58 (mean semiquantitative scores were between 0.18 and 0.67 ), in group II the mean quantitative scores were between 1.99 and 3.42 (mean semiquantitative scores between 1.27 and 1.92), whereas in group III the quantitative scores were between 7.33 and 11.59 (mean semiquantitative scores between 2.94 and 3.58). There were no significant differences between invasive lobular carcinomas and invasive ductal carcinomas, or between grades I, II, and III within these entities (Dunnet's test). The highest scores were recorded in invasive ductal carcinomas of grades II-III.
Table 3 Expression of IGFBP2 in invasive breast carcinoma according to hormone receptor status

\begin{tabular}{lll}
\hline & Semiquantitative & Quantitative \\
\hline ER+ & $3.18(0.13)$ & $9.74(0.74)$ \\
ER- & $3.37(0.11)$ & $10.35(0.75)$ \\
PR+ & $3.36(0.12)$ & $10.37(0.72)$ \\
PR- & $3.16(0.12)$ & $9.66(0.78)$ \\
Mann-Whitney test & NS & NS \\
$\quad$ ER+ $v$ ER- & NS & NS \\
PR+ $v$ PR- & & \\
\hline
\end{tabular}

Values are mean (SEM)

$E R$, oestrogen receptor; IGFBP2, insulin-like growth factor binding protein 2; NS, not significant; PR, progesterone receptor.

\section{Immunohistochemical images of malignant and benign entities}

As shown in fig 2A and B strong cytoplasmic staining for IGFBP2 was seen in the neoplastic cells of invasive ductal carcinoma. Weak, dot-like positivity for IGFBP2 was seen in 
ductal carcinoma in situ (fig 2C-E), whereas normal ducts showed no staining (fig $2 \mathrm{~F}$ ).

\section{Correlation between receptor status and IGFBP2}

No significant differences were found in the semiquantitative and quantitative scores of IGFBP2 expression in ER+ versus ER - tumours or PR+ versus PR - tumours of invasive carcinoma (Mann-Whitney test) (table 3). No correlation between ER or PR, and IGFBP2 could be seen when they were considered as continuous variables (data not shown).

\section{DISCUSSION}

The expression of growth factors and their receptors may be an important mechanism by which some cancers develop abnormal growth. Raised concentrations of IGFBP2 have been found in blood from patients with prostate carcinoma compared with those with benign prostatic hyperplasia, indicating a correlation between this protein and malignancy. ${ }^{15}$

In vitro studies using established breast tumour cell lines have suggested that tumours expressing IGF1 receptors may be responding, not only to circulating serum concentrations of IGFs produced by the liver, but also to IGFs produced by the tumour itself in an autocrine and/or paracrine manner. ${ }^{2}{ }^{16}$ Both IGF1 and IGF2 stimulate cell growth and are expressed in breast carcinomas. ${ }^{17}{ }^{18}$ The IGFBPs act by either enhancing or inhibiting the action of IGFs. ${ }^{19}$ The abundant and variable presence of the different IGFBPs in human breast tumours suggests that these molecules play a physiological role as modulators of IGF action in breast cancer. This effect may be different in different tumours, not only depending on which IGFBPs are expressed, but also on individual factors, such as age, concentrations of endogenous hormones, and menopausal status.

"The epithelial cells of invasive carcinoma expressed significantly more cytoplasmic insulin-like growth factor binding protein 2, compared with those of carcinoma in situ, hyperplasia, or normal glandular cells"

In our study, we have determined the expression of IGFBP2 in 120 specimens from women undergoing evaluation of breast pathology. To our knowledge, the expression of IGFBP2 in breast carcinoma has not been evaluated by immunohistochemistry previously. The epithelial cells of invasive carcinoma expressed significantly more cytoplasmic IGFBP2, compared with those of carcinoma in situ, hyperplasia, or normal glandular cells. This finding is in accordance with previous reports where IGFBP2 has been shown to augment the IGFl induced mitogenicity of cancer cells. ${ }^{20}$ Both IGF1 and IGF2 are thought to be partly synthesised by the stromal cells of the tumour, ${ }^{21}$ emphasising the importance of stromal-epithelial interactions in the control of breast cancer cell proliferation by IGFs.

Oestrogen positive breast cancer tumour cell lines have shown increased secretion of IGFBP2 compared with oestrogen negative cell lines. ${ }^{22}$ In our study, we did not find such an association between the ER status of the specimens and IGFBP2 expression. A more heterogeneous population of cells in human tumours and the selective properties of continuous cultures of tumour cell lines may account for this difference.

By extracting IGFBP2 protein from breast cancer specimens a ligand blot analysis revealed a positive correlation between the amount of IGFBP2 and the receptor status of the specimens. ${ }^{23}$ The difference between these studies can be explained by methodological variations. The immunohistochemical techniques used in our study measured the proteins expressed exclusively by the epithelial cells, ligand blot
Take home messages

- Using immunohistochemistry land quantitative and semiquantitative methods) no significant expression of insulin-like growth factor binding protein 2 (IGFBP2) was seen in normal breast glandular cells or breast hyperplasia

- IGFBP2 expression was gradually increased from hyperplasia through atypical hyperplasia and carcinoma in situ to invasive carcinoma

- No significant correlation was found between IGFBP2 immunostaining and oestrogen or progesterone receptor positivity within the malignant group

- IGFBP2 mitogenic signals of autocrine/paracrine regulatory mechanisms may be responsible for the growth of breast carcinomas, and IGFBP2 may be an independent indicator of malignancy

analysis measures the total amount of protein in the tumour tissue (stroma and neoplastic epithelial cells).

However, there were no significant differences in IGFBP2 expression between invasive lobular carcinomas and ductal carcinomas, or between grades I, II, and III within these entities. These findings are in agreement with the lack of a correlation between IGFBP2 and receptor status, because low grade of malignancy is positively correlated with ER positivity.

Both semiquantitative and a microcomputer based colour VIA technique revealed significant differences in the immunohistochemical expression of IGFBP2 between histological groups. The colour VIA technique for assessing immunohistochemistry staining provides an objective quantitative measurement of tissue features with high sensitivity and specificity. ${ }^{14}$ There was a good correlation between the colour VIA and semiquantitative analysis, despite the subjectivity involved in the second method.

These data suggest that IGFBP2 mitogenic signals of autocrine/paracrine regulatory mechanisms may be responsible for the growth of breast carcinomas, and that IGFBP2 is an independent indicator of malignancy. Because IGF and IGFBP signals are directly involved in the perturbation of the proliferative and apoptotic pathways of malignant growth, further examination of the relation between the IGF axis and tumorigenic processes will not only provide new insights into the intracellular mechanisms of cellular growth control, but raise the possibility of targeting components of the IGF system in cancer treatment.

\section{ACKNOWLEDGEMENTS}

This work was supported by the Norwegian Cancer Society and Aakre's Cancer Research Foundation.

\section{Authors' affiliations}

L-T Busund, E Richardsen, T Ukkonen, T Bjørnsen, H Stalsberg,

Department of Morphology, Institute of Medical Biology, University of Tromsø, N-9037 Tromsø, Norway and Department of Pathology, University Hospital of Northern Norway, N-9038 Tromsø, Norway R Busund, Department of Cardiovascular Surgery, Hospital of Northern Norway, N-9038 Tromsø, Norway and Institute of Clinical Medicine, University Tromsø

C Busch, Department of Pathology, University Hospital of Uppsala, SE75185 Uppsala, Sweden

\section{REFERENCES}

1 Zapf J, Froesch ER. Pathophysiological and clinical aspects of the insulin-like growth factors. Horm Res 1986;24:160-5. 
2 Daughaday WH. The possible autocrine/paracrine and endocrine roles of insulin-like growth factors of human tumors. Endocrinology 1990;127:1-4.

3 Delhanty PJ, Han VK. The characterization and expression of ovine insulinlike growth factor-binding protein-2. J Mol Endocrinol 1992;9:31-8.

4 Delhanty PJ, Han VK. The expression of insulin-like growth factor (IGF)binding protein-2 and IGF-II genes in the tissues of the developing ovine fetus. Endocrinology 1993;132:41-52.

5 Bourner MJ, Busby WH Jr, Siegel NR, et al. Cloning and sequence determination of bovine insulin-like growth factor binding protein-2 (IGFBP-2) comparison of its structural and functional properties with IGFBP-1. J Cell Biochem 1992;48:215-26.

6 Wood TL, Rogler L, Streck RD, et al. Targeted disruption of IGFBP-2 gene. Growth Regul 1993;3:5-8.

7 Reeve JG, Schwander J, Bleehen NM. IGFBP-2: an important regulator of insulin-like growth factor action in human lung tumours? Growth Regul 1993;3:82-4

8 Richardsen E, Ukkonen T, Bjornsen T, et al. Overexpression of IGFBP2 is a marker for malignant transformation in prostate epithelium. Virchows Arch 2003:442:329-35.

9 Busund LT, Ow KT, Russell P, et al. Expression of insulin-like growth factor mitogenic signals in adult soft-tissue sarcomas: significant correlation with malignant potential. Virchows Arch 2004;444:142-8.

10 Tavassoli FA, Devilee P. World Health Organization classification of tumors. Pathology and genetics of tumors of the breast and female genital organs. Lyon, France: IARC Press, 2003.

11 Elston CW, Ellis IO. Pathological prognostic factors in breast cancer. I. The value of histological grade in breast cancer: experience from a large study with long-term follow-up, Histopathology 1991;19:403-10.

12 Shousha S, Peston D. Immunohistochemical demonstration of oestrogen and progesterone receptors in paraffin sections of breast carcinoma. Current Diagnostic Pathology 1997;4:176-80.

13 Barnes DM, Harris WH, Smith P, et al. Immunohistochemical determination of oestrogen receptor: comparison of different methods of assessment of staining and correlation with clinical outcome of breast cancer patients. $\mathrm{Br} J$ Cancer 1996;74:1445-51.

14 Skinner JM, Zhao Y, Coventry B, et al. Video image analysis in pathology. Dis Markers 1993;11:53-70.

15 Ho JP, Baxter RC. Insulin-like growth factor-binding protein-2 in patients with prostate carcinoma and benign prostatic hyperplasia. Clin Endocrinol 1997;46: 145-54

16 El-Badry OM, Minniti C, Kohn EC, et al. Insulin-like growth factor II acts as an autocrine growth and motility factor in human rhabdomyosarcoma tumors. Cell Growth Differ 1990;1:325-31.

17 Cullen KJ, Allison A, Martire I, et al. Insulin-like growth factor expression in breast cancer epithelium and stroma. Breast Cancer Res Treat 1992;22:21-9.

18 Yee D, Paik S, Lebovic GS, et al. Analysis of insulin-like growth factor I gene expression in malignancy: evidence for a paracrine role in human breast cancer. Mol Endocrinol 1989;3:509-17.

19 DeMellow JSM, Baxter RC. Growth hormone dependent insulin-like growth factor binding protein both inhibits and potentiates IGF stimulated DNA synthesis in skin fibroblasts. Biochem Biophys Res Commun 1988; 156:199-204

20 Yee D, Favoni RE, Lupu R, et al. The insulin-like growth factor binding protein BP25 is expressed by human breast cancer cells. Biochem Biophys Res Commun 1989;158:38-44.

21 Manni A, Badger B, Wei L, et al. Hormonal regulation of insulin-like growth factor II and insulin-like growth factor binding protein expression by breast cancer cells in vivo: evidence for stromal epithelial interactions. Cancer Res $1984 ; 11: 2934-42$.

22 Clemmons DR, Camacho-Hubner C, Coronado E, et al. Insulin-like growth factor binding protein secretion by breast carcinoma cell lines: correlation with estrogen receptor status. Endocrinology 1990;127:2679-86.

23 Yee D, Sharma J, Hilsenbeck SG. Prognostic significance of insulin-like growth factor-binding protein expression in axillary lymph node-negative breast cancer. J Natl Cancer Inst 1994;23:1785-9. 